\title{
Michel de Montaigne: una crítica de la modernidad desde la reconciliación con la finitud
}

\author{
Víctor $\mathrm{H}$. Palacios Cruz \\ Universidad Católica Santo Toribio de Mogrovejo
}

Resumen

Montaigne traza una conciencia de la individualidad en un punto medio que evita tanto la deploración del yo del luteranismo como la absolutización de la razón del cartesianismo. Somos un punto en el tiempo y el espacio, pequeñez que desestima cualquier divinización del juicio personal y, de paso, explica la pluralidad del mundo. Pequeñez que alienta tanto el trato con la interioridad como el interés por los otros.

Palabras clave: conocimiento, escepticismo, racionalismo, modernidad, tolerancia.

\section{Abstract}

Montaigne fosters a sort of awareness of the individual, which is halfway in between the Lutheran denial of the self and the Carthesian absolutization of reason. We are just a tiny dot in time and space; a fact that prevents us from deifying our personal judgment and, in so doing, explains the plurality of the world. And this smallness encourages us both to care of our own intimacy, and to worry about the others.

Keywords: knowledge, scepticism, rationalism, modern age, tolerance. 
Contaba Nietzsche que cada vez que abría Los ensayos le crecía un ala o una pierna. Aquella única publicación de Michel de Montaigne (1533-1592) — divagatoria y miscelánea- creó una brecha entre los géneros de la literatura filosófica, historiográfica y didáctica del siglo XVI y, con esa mezcla de frescor y consistencia de los clásicos precoces, inició el periplo de un estilo que atravesó airoso las modas y goza aún de espléndida salud.

Los ensayos (Les essais) es el libro detrás de los grandes libros de la tradición europea. Es la presencia, callada o revulsiva, que se halla implícita en los Ensayos de Bacon, el Discurso del método de Descartes, los Pensamientos de Pascal, el Ensayo sobre el entendimiento humano de Locke, las Confesiones de Rousseau y otros. En una misiva a Louise Colet, Flaubert prorrumpe de este modo: "Estoy releyendo a Montaigne. ¡Es singular hasta qué punto estoy lleno de ese individuo! [...] Tenemos los mismos gustos, las mismas opiniones, la misma manera de vivir, las mismas manías. Hay gente a la que admiro más que a él, pero no hay a quien evocaría más a gusto, y con quien charlaría mejor” (2003: 37).

Su biógrafo, Jean Lacouture, habla de él como "uno de los fundadores de la introspección" y "uno de los inventores de la sensibilidad y de la cultura occidental" (2000: 11). Para Tzvetan Todorov, se trata del "primer verdadero humanista" en el sentido de aquel que piensa no que el humano es formidable, sino un ser indeterminado que tiene en la libertad la ocasión de su felicidad o su desdicha (2003: 166-167). En sus apuntes, Elias Canetti comenta: "Montaigne tiene esa actitud abierta hacia cualquier forma de vida humana que actualmente es universal y ha sido incluso elevada al rango de ciencia, pero él la tuvo en su época, una época fanáticamente convencida de su propia infalibilidad" (2008a: 284-285).

¿Es decir demasiado? Narrando un avatar muy castellano, Cervantes talló un arquetipo universal. De nuestro francés podría decirse que, tratando asuntos personales, alentado por sus lecturas 
predilectas y sin deseos de escribir más que para sus amigos y parientes, acumuló un grueso de folios que con incomparable amenidad anticiparon las referencias que la mentalidad europea, incluso contemporánea, ha aprendido a estimar: la conciencia de la individualidad, la defensa de la libertad, la exhortación al diálogo, el festejo de la pluralidad, el valor formativo de los viajes y el sentido inclusivo de la tolerancia. A lo que se añade la originalidad con que Montaigne profesa una consonancia entre la mesura aristotélica y el fervor de los amantes del mundo, entre la ignorancia socrática y la avidez de lecturas y de encuentros, y entre la certeza de la propia finitud y la sincera confianza en el infinito.

Si, como dice Sándor Marai (2006: 136 y 277), describiendo el implacable proceso de despersonalización de la sociedad húngara bajo la ocupación comunista, el mayor de los aportes del Viejo Continente a la historia es la consolidación del individuo y del sentimiento burgués —entendido no como una autocomplacencia social sino como el cultivo decidido de la propia alma-, no cabe la menor duda de que Montaigne es un prócer de la cultura europea y una luz para este tiempo.

\section{Crítica del orgullo de la razón}

A poco de nacer, el pequeño Michel fue enviado por su padre, Pierre Eyquem, a la casa de unos leñadores de sus tierras, en Perigord (Gascuńa), para dar sus primeros pasos y adquirir desde la más temprana edad familiaridad con la carestía y la austeridad de las gentes más modestas. Al volver al castillo, recibió de inmediato una esmerada iniciación en la lengua latina, la lectura de los clásicos y la cortesía, a cargo de unos preceptores humanistas contratados por su progenitor con la intención de afinar su alma tras su ejercitación en la reciedumbre. Tiempo después, Montaigne con- 
fesaría que tan pronto lee a Cicerón como escucha con atención a cualquiera de sus campesinos.

Poco a poco, Pierre reunió una copiosa biblioteca que demarcaría el lugar más entrañable de la soledad y las meditaciones de su hijo, enamorado al mismo tiempo de los viajes y dedicado sucesivamente al oficio de las leyes y a la alcaldía de Bourdeaux. En uno de sus periodos de recogimiento, tras la muerte del amado padre, las puertas del castillo fueron aporreadas por la noticia de las carnicerías de la Noche de San Bartolomé (agosto de 1572), en que miles de hugonotes perecieron a manos de enceguecidos católicos en el curso de unas feroces guerras de religión; no obstante lo cual, el autor de Los ensayos jamás perdió las ganas de salir al mundo y acercarse, como él diría, a lugares donde "rozar y limar nuestro cerebro con el de otros", en una inusitada actitud de celebración del mundo en una época de espanto.

Apenas publicada la primera edición de su obra (1580), emprendió un largo recorrido a caballo por poblados y campiñas de Francia, Alemania, Suiza e Italia. Cuando en Roma le contaron que allí residían algunos gascones, él contestó: "para qué quiero verlos si ya tengo bastantes en mi país", y en esa misma ciudad pidió que le dejaran presenciar una ceremonia de circuncisión en una sinagoga. "No conozco mejor escuela para formar la vida, como he dicho a menudo, que presentarle sin cesar la variedad de tantas vidas, fantasías y costumbres diferentes, y darle a probar la tan perpetua variedad de formas de nuestra naturaleza" (Montaigne, 2007: 1451).

De su andar aquí y allá, entre los humildes labriegos o en las cortes más suntuosas, envuelto por los libros de su torre o cabalgando a placer porque "cualquier cielo me va bien", entregado juiciosamente a la vida pública u ocupado en la escritura de sus experiencias y el conocimiento de sí mismo; en fin, de una oscilación que no es eclecticismo ni contradicción sino grandeza y 
versatilidad, proviene, sin duda, ese diáfano sentido común que los lectores suelen agradecer en Michel de Montaigne.

Podrá defraudar a quienes no hayan leído Los ensayos decir que esto sea lo mejor de su joyero. Pero desde Hannah Arendt y su meticuloso estudio de la mentalidad moderna que culmina en la insania de los totalitarismos, ${ }^{1}$ sabemos bien que la sensatez y el buen juicio conforman una de esas piezas cuya ausencia podría costar a la sociedad incluso la hecatombe, y que la predominancia de la pura lógica puede enrarecer y aun imposibilitar la convivencia. Los últimos cien años nos han advertido sonoramente que una larga acumulación de ciencia y técnica no garantiza la perpetuidad de la concordia, y que en cualquier punto de la delicada red de lo cotidiano puede abrirse un intersticio por donde emerja de nuevo la barbarie.

El siglo XVI discurría ciertamente estremecido por una muchedumbre de trastornos (guerras civiles, descubrimientos geográficos, discusión de la vieja astronomía, protestantismo, declive del feudalismo), en medio de los cuales Michel de Montaigne preservó el ángulo de una mirada distante y amplia, a la vez que cálida: "El cielo y las estrellas se han movido durante tres mil años -escribe (2007: 855)—; todo el mundo lo había creído así hasta que a Cleantes de Samos o, según Teofrasto, Nicetas de Siracusa se le ocurrió sostener que era la Tierra la que se movía por el círculo oblicuo del zodiaco, girando en torno a su eje. Y, en nuestros tiempos, Copérnico ha fundamentado tan bien esta doctrina, que se sirve de ella con gran precisión para todas las consecuencias astronómicas. ¿Qué sacaremos de ahí sino que no debe importarnos cuál sea de las dos? Y ¿quién sabe si una tercera opinión, de aquí a mil años, no derribará a las dos precedentes?”.

${ }^{1}$ Sus estudios Los orígenes del totalitarismo y Eichmann en Jerusalén son pertinentes al respecto. 
No es la exposición de una postura simplemente equidistante. Tampoco la expresión de una indolencia. Se trata, más bien, de una cautela ante los extremos en juego, tanto la ciega afirmación de lo nuevo como la sujeción incondicional a lo viejo. Prudencia natural en quien, instruido en la variedad del mundo, censura toda aseveración categórica. Cuando surge una nueva doctrina, prosigue el jinete gascón, "tenemos un gran motivo para desconfiar de ella y considerar que antes de que fuese producida, su contraria estaba en boga; y que, de la misma manera que ésta fue derribada por aquélla, podrá surgir en el futuro una tercera invención que se opondrá igualmente a la segunda. Antes de que los principios que introdujo Aristóteles gozaran de aceptación, otros principios satisfacían la razón humana, tal como éstos nos satisfacen hoy en día. ¿Qué títulos poseen éstos, qué privilegio particular, para que el curso de nuestra invención se detenga en ellos, y para que les corresponda dominar por siempre jamás nuestra creencia? No son más inmunes al rechazo que sus antecesores" (2007: 856).

El Dante de la Divina comedia había anticipado esta sencillez en el recelo de cualquier dogmatismo: “Es la humana excelencia cosa huera / y en su cima el verdor muy poco dura / si no le siguen tiempos de ceguera! / Creía Cimabúe en la pintura / tener el campo, que ahora es mantenido / por Giotto, que su fama vuelve oscura; / así quitóle el uno al otro Guido / la gloria de la lengua; y tal vez viva / quien a los dos arrojará del nido" (Alighieri, 2004: 458).

El mundo es inabarcable. ¿Y quién ha tocado el fondo de sí mismo?, preguntaba en sus Confesiones san Agustín. Si las ideas, como la vida misma, cambian, a qué convertir cada una en un monumento solo a causa del deceso de otras. Muchas veces no son los autores los que ambicionan la entronización, sino sus prosélitos y divulgadores. Cuántos que peroran sobre Tomás de Aquino o Karl Marx son más consultados que estos mismos. Aristóteles afirmaba, en la primera línea de su Metafísica, que "todo hombre por 
naturaleza desea saber". Para Montaigne, el inconveniente no es el deseo sino la incontinencia: "la primera tentación que el diablo presentó a la naturaleza humana, su primera ponzoña, se introdujo en nosotros merced a las promesas de ciencia y conocimiento que nos hizo: 'Seréis como dioses, conocedores del bien y del mal'. Y las sirenas, para engañar a Ulises, en Homero, y para atraerlo a sus peligrosos y destructivos lazos, le ofrecen la ciencia como don. La peste del hombre es el convencimiento de saber" (Montaigne, 2007: 712-713). Por algo el Estagirita se cuida de escribir que "todo hombre por naturaleza sabe o llegará a saber".

El peligro que turba al autor de Les essais no es otro que el que puede entreverse en el caso de Lutero: el atribuir fundamento divino al propio juicio. De donde no podría sino seguirse la superfluidad del diálogo y la intolerancia. La instigación diabólica en el Génesis ofrece la emulación de la visión divina que es, en definitiva, la supresión del anhelo de saber que pone al humano en movimiento. "El afán de progresar en sabiduría y en ciencia agrega Montaigne (2007: 730) — fue la primera ruina del género humano; es la vía por la cual se ha precipitado a la condena eterna. El orgullo es su pérdida y su corrupción”. Hay que notar la osadía que tienen estas exclamaciones en un tiempo todavía asombrado por las proezas de los navegantes, los conquistadores, los artistas y los científicos que encarnan esa intrepidez connatural al Renacimiento.

Décadas antes, un tempranamente desengañado Erasmo de Rotterdam había deplorado los desenfrenos de sus coetáneos con bastante energía como para componer un Elogio de la locura, en el que se alude a la ciencia como a una fuente de melancolía, según un tópico que se remonta al menos al Eclesiastés y que Alberto Durero, en 1514, acababa de representar en un grabado homónimo. "Cuanta menos sabiduría se tiene, más feliz se es", declaraba Sófocles. 
Saber vivir, sostiene Montaigne, es circunscribirnos como criaturas, aceptar con hidalguía nuestra contingencia. No tiene desperdicio, a este respecto, una cita del Elogio de la locura que da fe del humor que le valió seguramente el éxito de que gozó: Las "sutilezas sutilísimas" de los doctos "las convierten en archisutiles las vías escolásticas, ya que antes se saldría de un laberinto que de esa maraña de realistas, nominalistas, tomistas, albertistas, occamistas, escotistas y no he nombrado sino las principales escuelas. En todas ellas es tanta la erudición y tantas las dificultades, que los mismos apóstoles juzgarían necesaria una nueva venida del Espíritu Santo si tuvieran que disputar de tales temas con este nuevo género de teólogos. [...] a mi juicio, procederían cuerdamente los cristianos si en vez de enviar contra turcos y sarracenos esas falanges de soldados, con las que desde hace tiempo los combaten con varia fortuna, enviaran a los alborotadores escotistas, a los obstinadísimos occamistas y a los invictos albertistas, junto con toda la multitud de los sofistas: creo que presenciarían la más divertida batalla y una victoria nunca vista" (1999: 71).

Diatribas semejantes prueban el hastío que habían llegado a provocar las aparatosas disquisiciones de la Escolástica que, por entonces, languidecía en escuelas y universidades y de la que, poco después, Descartes y Locke harán sus propios vilipendios. Por contagio, este desprestigio involucró a Aristóteles, el Filósofo como lo llamaba santo Tomás. El mismo Montaigne cae en el lugar común al dirigir imprecaciones contra la dialéctica del alumno de Platón. Galileo, en cambio, con un sentido de la justicia destacable por el calor del momento, adjudica los desvaríos del aristotelismo a sus exégetas antes que al propio estagirita, a quien disculpa por la pobreza de los medios científicos de que pudo disponer (Sciacca, 1966: 117). ${ }^{2}$

2 "No hay duda de que Aristóteles, a diferencia de sus 'demasiado pusilánimes secuaces', 'si hubiera conocido las novedades descubiertas en el Cielo, habría 
Después de todo, las cosas se pondrían del todo en su lugar si se recordara la raíz léxica de la palabra filosofía, con la que se había designado a toda ciencia a lo largo de centurias, y que indica apenas "amor a la sabiduría". "Amor", no "posesión”, ni mucho menos alarde. Ninguna disciplina tuvo nunca mejor nombre. Bellamente, Proust alega que "el deseo aviva las cosas y la posesión las marchita”.

Un estado solo anhelante comporta, es cierto, una carencia, incluso la ignorancia universal. Pero Montaigne se apresura a proclamarla como inherente y preferible para nuestra condición: "yo, que no profeso otra cosa, encuentro en [el no saber] una profundidad y variedad tan infinita, que mi aprendizaje no saca otro provecho que hacerme sentir cuánto me queda por aprender. Debo a mi flaqueza, tantas veces reconocida, mi inclinación a la modestia, a la obediencia de las creencias que me están prescritas, a una constante frialdad y moderación de opiniones; y el odio a la arrogancia importuna y pendenciera, que se cree y se fía plenamente de sí misma, enemiga mortal de la enseńanza de la verdad". Por ello, "la humana ignorancia por experiencia” es, "a mi juicio, el más seguro partido de la escuela del mundo" (Montaigne, 2007: 1606). Y nada más contrario a la verdad que el obstinado apego a una idea o a uno mismo.

A Sócrates la demostración práctica de este "no saber" bajo los pórticos de Atenas, le costó el despecho de sus adversarios puestos en evidencia y, en su senectud, acusaciones calumniosas que el tribunal de la polis tradujo en su condena, según narra la conmove-

cambiado de opinión, habría enmendado sus libros y se habría acercado a las doctrinas más sensatas', porque es absurdo suponer que él quisiera que "sus decretos fueran antepuestos a los sentidos, a las experiencias y a la misma naturaleza'. Por tanto, 'son sus seguidores los que han dado la autoridad a él, y no Aristóteles quien la haya usurpado o robado..., y antes de introducir una alteración en el Cielo de Aristóteles pretenden con impertinencia negar lo que ven en el Cielo de la naturaleza”" (citado por Sciacca, 1996: 117). 
dora Apología. El oráculo de Delfos había anunciado que Sócrates era el más sabio de los hombres. Ante el estupor del aludido, no hubo para él forma de entender la respuesta de la Pitia que no fuera admitiendo el hecho de que todos los mortales ignoramos e ignoraremos siempre, pero que ignoraremos menos, y por tanto algo sabremos, cuando lleguemos a aceptarlo.

Consecuentemente, para Montaigne es mejor fiarnos de la naturaleza recibida antes que de las sofisticaciones de la inteligencia. La experiencia, la relación espontánea con las cosas, es mejor consejera que los malabares de nuestros silogismos: "en este Universo —escribe (2007: 1603)—, me dejo llevar, de manera ignorante y negligente, por la ley general del mundo. La conoceré bastante mientras la sienta. Mi ciencia no puede hacerle cambiar de ruta. No va a variar por mí. Es una locura esperarlo, y una mayor locura inquietarse por ello, puesto que necesariamente es uniforme, general y común". Por tanto, "iqué dulce y blanda almohada, y qué sana, la ignorancia y la falta de curiosidad, para reposar una cabeza bien formada! Preferiría ser un entendido en mí mismo a serlo en Cicerón. Con mi experiencia sobre mí me basta para hacerme sabio, si fuese buen estudiante".

El viajero perigordino se limita, pues, a seguir esa fluida interioridad sin ejercer sobre ella un control que la desvirtuaría. René Descartes (1596-1650), en cambio, se propondrá acallarlo todo a su alrededor para escuchar "la sola voz de la razón" y desplegarla por entero con la ilusión de obtener un saber exhaustivo que "solucione de manera general todos los problemas de los hombres". En el Discurso del método hay como una inapagable codicia que recuerda el robo del fuego de los dioses. Descartes es también testigo de un escenario de escombros, de saberes desmentidos y sistemas derribados en el inicio de la modernidad, y su reacción es la de una voluntad de reconstrucción definitiva, de una ciencia que nunca más vuelva a caer. A su lado, Montaigne es la reconciliación con lo 
inacabado y con la inexorable mudanza del juicio terreno, en una serena aceptación de nuestra finitud. ${ }^{3}$

Llamativamente, en el siglo XIX, delante de la marcha boyante de un racionalismo que había superado la crítica del romanticismo a la razón ilustrada, y renovado su progresión en el cientificismo y el industrialismo, Schopenhauer hablará de la conciencia como de una facultad entorpecedora de la vida y un factor del aumento de nuestras pesadumbres; en tanto que Eça de Queirós, en uno de sus relatos — “Adán y Eva en el paraíso”- verá en las obsesiones de la razón un motivo para envidiar la inocencia de los animales sumidos en el silencio, cuya existencia transcurre dulcemente sin conflictos ni cuestionamientos.

Comenta Erasmo (1999: 44-45) nuevamente: "los hombres más felices son los que consiguen abstenerse por completo de todo trato con el saber y se gobiernan únicamente por los dictados de la naturaleza que en nada nos falta a menos que queramos traspasar los límites de la condición mortal. La naturaleza odia al artificio y se muestra más hermosa allí donde jamás ha sido profanada. [...] ¡Cuánto mejor es la vida de las moscas y de las aves, entregadas al azar y al instinto natural en la medida en que se lo permiten las insidias de los hombres! Si metéis un pájaro en una jaula y le enseñáis a remedar la voz humana, perderá su canto la gracia natural. Hasta ese punto es siempre más hermoso lo que produce la naturaleza que lo que finge el arte".

${ }^{3}$ No obstante las notorias contraposiciones entre ambos franceses a quienes se atribuye la instauración de la subjetividad moderna, es justo decir que Descartes fue un lector asiduo de Los ensayos de los que tomó, muy verosímilmente, la preferencia por la lengua francesa, la escritura en primera persona y el tono testimonial y autobiográfico en la exposición de las ideas. Para Etienne Gilson, el Discurso del método es la réplica enérgica a los textos de Montaigne y "una lucha desesperada por salir de su escepticismo" (199: 114 y ss.) 


\section{Finitud humana, variedad del mundo y perspectivismo}

Somos finitos. ¿Cómo podríamos verlo todo? "Parece que la naturaleza, como consuelo a nuestro miserable y pobre estado, no nos ha concedido otra cosa que la presunción. Así lo dice Epicteto: el hombre no tiene nada propiamente suyo sino el uso de sus opiniones. No se nos ha asignado sino viento y humo" (Montaigne, 2007: 714). Y añade, más adelante: "la santa palabra declara miserables a aquellos de entre nosotros que se estiman: 'Cieno y ceniza', les dice, '¿qué tienes para enorgullecerte?' Y en otro sitio: 'Dios ha hecho al hombre semejante a la sombra; ¿quién pensará en ella cuando, al retirarse la luz, se desvanezca?' No somos nada" (p. 731).

Humo, viento, cieno, ceniza, sombra, nada... ¿Está el escritor del castillo embargado por las brumas de un pesimismo luterano? Montaigne acude a los autores, se traslada a los países, no rechaza nada, todo le atrae y le anima a cabalgar. Dice que no sabemos, pero lee con fervor y escribe regocijado; dice que somos una nulidad pero recomienda seguir la propia naturaleza. El esclarecimiento solo puede venir de entender que su propósito es otro que el del reformista alemán. La rudeza de sus vocablos no es en rigor la desautorización de nuestras luces, sino el recordatorio de que nuestras flaquezas deben inhibirnos de querer poner en todo el punto final. Nada desasosiega tanto a Montaigne como la petulancia y la altivez.

Se ha visto antes la comicidad con que Erasmo achacaba a los teólogos sus demasías, creyendo poder explicar con prolijidad hasta las intimidades de lo divino. Montaigne añade, citando a san Agustín, que "se conoce mejor a Dios no conociéndolo". Antes del Elogio de la locura, el obispo Nicolás de Cusa (1401-1464) había referido la conveniencia de una docta ignorancia, un saber de nuestro no poder saber que, entre otras cosas, recomienda la 
discreción de una teología negativa para la cual más sabemos de Dios lo que no es que lo que es (Cusa, 1984: 81-83). La obvia eminencia de lo sobrenatural determina su inefabilidad, por tanto la incompetencia de nuestro intelecto y nuestro lenguaje para abordarlo con rotundidad.

El trasponer nuestra medida nos abismaría en un antropocentrismo que acabaría confundiendo la naturaleza de Dios o la de otros seres con la nuestra (el "dios de los filósofos", del que abominaba Pascal). "Decimos que Dios teme, que Dios se enfurece, que Dios ama, designando cosas inmortales con palabras mortales", cuando "solo a Dios le corresponde conocerse e interpretar sus obras", se lee en Los ensayos (pp. 731-732). Hay, al respecto, un antiguo argumento atribuido a Jenófanes y citado por Karl Popper (2006: 798): "los etíopes dicen que sus dioses tienen la nariz chata y negra, mientras que los tracios dicen que los suyos tienen ojos azules y pelo rojo. Si las vacas, los caballos o los leones tuviesen manos y pudiesen dibujar y esculpir como los hombres, entonces los caballos dibujarían a sus dioses como caballos y las vacas como vacas; cada uno de ellos moldearía los cuerpos de los dioses a su imagen y semejanza”.

Es interesante ver que así como la teoría de la relatividad de Einstein produjo en el siglo XX fuertes sacudidas en la consideración de la ciencia occidental y la cultura europea, otro hallazgo científico, no tanto la confirmación del heliocentrismo cuanto - para decirlo a la manera de Popper - el descarte de la tesis ptolemaica según la cual la Tierra es el centro del cosmos, llegó en verdad a remecer la misma posibilidad de la teoría y la certeza. ${ }^{4}$ Montaigne hace una reconvención muy gráfica en ese sentido: esta criatura "se siente y

\footnotetext{
${ }^{4}$ Cassirer y Popkin "subrayan el papel fundamental del escepticismo en la génesis y el desarrollo de la Modernidad: sin la crisis escéptica del Renacimiento, ya presente en figuras como Agrippa von Nettesheim o Nicolás de Cusa, y desarrollado ampliamente por el pirronismo de la 'Apología' [de Montaigne] o el
} 
se ve alojada aquí, entre el cieno y las heces del mundo, adherida y fijada a la peor, más muerta y más corrupta parte del universo, en la última planta de la casa y la más distante de la bóveda celeste, junto a los animales de la peor condición de los tres, y se instala con la imaginación más allá del círculo de la luna, y pone el cielo bajo sus pies. Por la vanidad de esta misma imaginación, se iguala a Dios, se adjudica las condiciones divinas, se distingue a sí mismo y se desgaja de la muchedumbre de las demás criaturas" (2007: 654).

Creo que más acuciante que ver en estos términos un ataque a la definición del Discurso sobre la dignidad del hombre (1486) de Pico de la Mirandola sobre la "más admirable" de las criaturas del universo - "vocero de todas las criaturas", "puente entre la eternidad estable y el tiempo fluyente" — es compaginar esta advertencia con la ya aludida confianza que Montaigne deposita en la experiencia de cada cual. "La enfermedad más ruin es el desprecio de nuestro ser", asegura.

A todo esto, hay que decir que el jinete gascón se abstiene en todo momento de llamarse filósofo. Por eso, se cuida de esquematizar sus observaciones y opta al escribir por una soltura que, sin querer, lo conduce por los aledańos de la contradicción, lo que, sin restarle crédito, más bien agrega a su discurso una cierta naturalidad.

Pues bien, para Montaigne esa fiabilidad de la condición personal tiene absoluta licencia siempre y cuando no se haga de ella una potencia completa y autónoma. He ahí lo decisivo. Si cada uno es solo un punto en el tiempo y el espacio, ¿cómo pretender sacralizar nuestros pronunciamientos? Simultáneamente, si cada vida es fragmentaria, por lo mismo es también irreemplazable. No se le debe pleitesía al propio juicio, pero tampoco se lo puede desestimar tajantemente. No agotamos en nuestra pequeñez las posi-

Quod nihil scitur de Sánchez, sería difícil concebir la necesidad de certeza que se impuso a mediados del siglo XVII" (Navarro, 2007: 32) 
bilidades que albergamos, pero nadie más vivirá y experimentará lo que un individuo en el variable plazo de su existencia. Todos trazamos trayectos cortos pero propios, y por esta razón se escriben biografías.

Aristóteles, también en la Metafísica (1998: 84-87), argüía que lo que descubre uno solo por su cuenta es desdeńable, pero lo que se reúne entre varios es ya de apreciable magnitud. De modo que "nadie yerra por completo" y ningún punto de vista es irrelevante. La finitud explica, más aún, la maravillosa desigualdad de los humanos y la constante mudabilidad de las prácticas y las creencias. Cada ciencia es temporal, sujeta a los medios del investigador y su circunstancia. Cada planteamiento recoge una única oportunidad y aporta algo que se suma sin llegar a serlo todo. El más grave error sería contentarnos con nuestra parcela.

La posición de Montaigne, además de ser un examen de su época, pareciera presentir los futuros desbordes de esa embriaguez moderna desatada, por ejemplo, en la metafísica omnisciente de los racionalistas del siglo XVII, en el presentismo de la Ilustración orgullosa y en el amplio programa político que pretende traducir la ciencia en el más irrestricto bienestar social en la cultura decimonónica. Justamente en esta última centuria, que es como una antesala de los horrores del siglo XX, tintas diversas como las de Baudelaire, Bloy, Nietzsche o Flaubert, diagnostican con mayor crispación lo que el autor de Les essais ya había lamentado. Dice el autor de Madame Bovary (2003: 374) "soy de la opinión de Montaigne, mi padre nutricio: creo que jamás se nos puede despreciar lo bastante, conforme a nuestro mérito. Me gusta ver la humanidad y todo lo que respeta rebajado, escarnecido, deshonrado, abucheado. Por ese lado siento alguna ternura por los ascéticos. El torpor moderno viene del respeto ilimitado que tiene el hombre por sí mismo". 
Redactados delante de las hinchazones de su tiempo, Los ensayos producen la sensación de un lenitivo, un jarabe dulce y sedante que aplaca nuestras ínfulas y refresca con ese aire libre del amor a la verdad que, de paso, nos impide decir para siempre en cualquier filosofía. "Cuando juego con mi gata, quién sabe si es ella la que pasa el tiempo conmigo más que yo con ella", dice un Montaigne (2007: 655) precavido que no olvida la restricción de la propia mirada.

En efecto, numerosas visiones cruzan la calle, no coinciden entre sí, pero todas ellas tienen razón. ¿Relativismo? No, más bien perspectivismo. Sería irresponsable el juez que resuelva un caso considerando uno solo de los testimonios. Como sostiene Arendt en La condición humana (1993: 221-222) la salud del juicio personal consiste en incorporar las captaciones de otros que comparten nuestro mundo, que lo habitan y atraviesan de otros modos que, de paso, ratifican la objetividad de aquello que observamos como algo que existe al margen de nuestra percepción. Porque el mundo es poliédrico, ninguna posición lo abarca entero, y es la concurrencia de otros lo que lo hace real aun para uno mismo. El relativismo es, por el contrario, la indiferencia de las particularidades complacidas, la reclusión conformista y la renuncia a la comunicación. Como intuía Todorov, toda conversación empieza necesariamente alentada por una expectativa de verdad.

De la policromía del mundo se infiere la riqueza del encuentro. "En la escuela de las relaciones humanas - se lee en Les essais (2007: 196) — , he observado con frecuencia el vicio de que, en lugar de dedicarnos a conocer a los demás, solo nos esforzamos en darnos a conocer, y nos preocupamos más por despachar nuestra mercancía que por adquirir una nueva. El silencio y la modestia son cualidades muy convenientes en el trato con los demás". La finitud no es desaliento sino avidez. 
Ante la pluralidad de las visiones, el disentimiento es lo esperable y de ningún modo una obstrucción. Por el contrario, es el mejor argumento para la cordialidad y la atención sincera al otro, pues la disparidad garantiza la ganancia del convite. "Cuando me llevan la contraria - declara Montaigne-, despiertan mi atención, no mi cólera; me ofrezco a quien me contradice, que me instruye. La causa de la verdad debería ser la causa común de uno y otro". Por eso, nada detesta tanto el maestro a caballo como la lisonja de los otros o el miedo a enmendar que suele sentir quien confunde la amistad con la aquiescencia: "busco más el trato de quienes me reprenden que el de quienes me temen. Es un placer insípido y nocivo tener relación con gente que nos admira y nos cede el sitio" (Montaigne, 2007: 1380-1381).

La charla no viene a ser sino el canje de nuestros respectivos pedacitos de mundo y la certidumbre de la propia estrechez es el mejor pretexto para la convocatoria y la urbanidad. Montaigne es, por ello, una plácida lección de hospitalidad y de civismo en una sociedad, como la nuestra, inclinada hacia el encierro tecnológico, el narcisismo consumista y la impaciencia para el diálogo y el trabajo en equipo que no son otra cosa que el sistema circulatorio de lo que llamamos civilización.

\section{Escepticismo moderado y optimista}

\footnotetext{
5 "No se trata de eliminar todo valor, en sentido fuerte, para dirimir la conversación en un terreno de indiferencia subjetivista, sino de permitir que las disensiones sean aceptadas por los hablantes no ya sin crispación, sino con auténtico interés. Solo así es posible corregir al otro sin imponerle imperativamente la propia opinión, como si fuera la única verdad ante la que hubiera de quedar subyugado. Gracias a la confrontación con la diferencia está en nuestra mano impedir que nuestras opiniones se petrifiquen, adoptando la apariencia de verdades absolutas" (Navarro, 2007: 314).
} 
Pitágoras, Parménides, Heráclito, Sócrates, Platón y Aristóteles, en ese orden y a pesar de sus diferencias, creían con unanimidad que la sabiduría estaba exclusivamente en manos de los dioses y que a los mortales correspondía únicamente la interrogación y el anhelo. Las alegorías de que se vale Platón cuando habla del alma o del más allá son, como todas las metáforas, articulaciones que sugieren y, a la vez, dejan fuera una totalidad que las rebasa. Dentro de esta misma tradición, Montaigne reafirma: "nuestra sabiduría no es más que locura ante los ojos de Dios” (2007: 647-648).

Es cierto que bajo esta luz todos los pareceres quedan allanados, pero también lo es que de esa forma cualquier despotismo queda derogado. "Sea lo que fuere lo que nos predican - arguye el pensador del castillo-, sea lo que fuere lo que aprendemos, habría que recordar siempre que es el hombre quien da y el hombre quien recibe; es una mano mortal la que nos lo ofrece, es una mano mortal la que lo acepta. Solo las cosas que nos llegan del cielo tienen derecho y autoridad de persuasión" (Montaigne, 2007: 845).

¿Ello significa que debemos bajar los brazos y desplomarnos en nuestra inanidad, puesto que es inútil el esmero e infructuosa toda búsqueda? Admirablemente, el escritor del castillo responde: "la persecución y la caza corren propiamente de nuestra cuenta; no tenemos excusa si la efectuamos mal y con impertinencia. Fallar en la captura es otra cosa. Porque hemos nacido para buscar la verdad; poseerla corresponde a una potencia mayor. No está, como decía Demócrito, escondida en el fondo de los abismos, sino más bien encumbrada a una altura infinita en el conocimiento divino. El mundo es solo una escuela de indagación. La cuestión no es quién llegará a la meta, sino quién efectuará las más bellas carreras" (Montaigne, 2007: 1385). La imposibilidad de consumar el saber es, entonces, la legitimación de todos los caminos, en tanto que llevados con rectitud y aplicación. Un justo medio entre el desaliento ante la propia iniciativa y la irreverencia ante la voz de los demás. 
En sus ideas y sus cuentos, Julio Ramón Ribeyro (2009: 66) ilustra que el escepticismo no es una frivolidad ni un abandono, sino una búsqueda cuya constante insatisfacción es la prueba de la enormidad de lo buscado. Parecidamente, Merleau Ponty propugnaba que el buen escéptico está siempre en "movimiento hacia la verdad”. Cuenta Jesús Navarro (2007: 292) que Francisco Sánchez, autor del Que nada se sabe, "a pesar de ser contemporáneo de Montaigne y de pasar la mayor parte de su vida en el sur de Francia no parece que conociera la obra del ensayista, comparte no obstante la misma actitud gnoseológica: 'no te prometo absolutamente la Verdad, pues la ignoro como todo lo demás; pero en la medida en que pueda he de perseguirla. Tú mismo la perseguirás [...] mas no esperes atraparla nunca ni poseerla a sabiendas; bástete lo mismo que a mí: acosarla. Éste es mi objetivo, éste mi fin, éste ha de ser también el que tú debes buscar".

La filosofía, como en Sócrates, es conjetura, opinión, duda, un preguntar sin fatigas; jamás un círculo cerrado, un patrimonio terminado como el que concibe Descartes en su proyecto personal. Incluso el temperamento de Montaigne le lleva a soslayar el procedimiento sistemático al sentarse ante el papel. Un sistema comporta cierta solidificación, una circularidad que se contaminaría con la apertura. En sus Apuntes, Elias Canetti (2008b: 153) alegaba confluyentemente que "cuanto más riguroso y consecuente es un pensamiento, más distorsionada es la visión que ofrece del mundo". El amor a la verdad — philos-sophia— es, como el buen compromiso, la presteza para la acción y no una displicente quietud. Flexibilidad, aptitud para el cambio y la adaptación, para la incorporación de lo distinto e imponderable.

Lo propio del buscador es un carácter habituado a la fluctuación de los terrenos, un temple apto para auparse a lomos del fluir de las cosas como sobre una cabalgadura sin senderos prefijados. Hegel decía con razón que el escéptico no puede tener un yo débil, 
sino necesariamente fuerte (Bürger, C. y P. Bürger, 2001: 34). Un porte que, sin embargo, no implica la dureza de lo férreo. En Antígona (2007: 265), Sófocles pregona: "cuando se sueltan indomables los torrentes de invierno, los árboles que doblan flexibles sus ramas, permanecen incólumes, en tanto que los que se muestran rígidos e indoblegables, son arrancados desde sus raíces" ${ }^{6}$

Ensayo connotaba en tiempos de Montaigne el pesaje o la mensura que hacía el químico para catar sus insumos. De ahora en adelante esta palabra querrá decir "probar" en un sentido diferente: llevar a cabo una práctica sin carácter definitivo, dar una performance provisional o brindar una prestación mejorable. Intento, tentativa. Como la vida misma: estar en la ruta, cabalgar más que desmontar.

Al maestro a caballo lo enfurece el modo cómo Aristóteles se mofa de Pirrón de Elis que predicaba esta indefinición del pensamiento y a quien el estagirita exige, como algo consecuente con su renuncia a la certeza, la inmovilidad de una planta. El pirronismo, según el francés, plantea una conducta más bien civilizada al tratar de combatir la prepotencia de las doctrinas, sin que ello conlleve dimitir del pensamiento.

Montaigne quiere dudar de todo y, en primer lugar, de sí mismo, al punto que no tiene problema alguno en descalificar sus propios ensayos: "sin que importe cómo son estas sandeces, quiero decir que no he pensado en esconderlas, como tampoco escondería un retrato que me mostrara calvo y canoso, en el cual el pintor hubiera fijado no un semblante perfecto sino el mío. Porque también

6 "No te aferres a tus opiniones. No tengas por verdad inapelable lo que tú piensas. No eres el dueńo de la verdad. Y aquellos que se obstinan en ser sabios sobre todos, sabios únicos, y tener una palabra que vence, si los sometemos a prueba resultan vacíos. Podrá muy sabio ser un hombre: jamás es para él una afrenta el recibir sabiduría de otros y no ser demasiado apegado a sus pareceres". (Sófocles, 2007: 265) 
éstas son mis inclinaciones y mis opiniones. Las ofrezco como lo que yo creo, no como aquello que debe creerse. [...] No poseo la autoridad de ser creído, ni lo deseo, pues siento que estoy demasiado mal instruido para instruir a los demás" (Montaigne, 2007: 186-187). Escribe no para ceñir una posición y cubrir inobjetablemente un tema. Escribe para inquirir, para moverse. Ensaya, en suma. Y puesto que vivir es estar en movimiento, su obra nunca culmina excepto con la muerte, como efectivamente ocurre al corregir una y otra vez un ejemplar de su obra. Cada frase es como cada paso que va haciendo la vida, sin figuras preconcebidas ni destinos preestablecidos, siendo y haciéndose en el mismo acto.

Hay que insistir en que su escepticismo no es una embestida contra la confianza en la verdad. Es una resistencia contra los falseamientos del interrumpir la marcha en un punto que es solo paradero. Un celo contra cualquier absolutización de lo humano. Si la filosofía es amor a la sabiduría, o sea amor a la verdad, es entonces fidelidad a las cosas antes que al vapor de los conceptos. Y si las cosas, fuera y dentro de uno mismo, no son ni macizas ni estáticas, ese deber requerirá la ductilidad para despojarnos de nuestras nociones previas e ir de nuevo hacia adelante, hacia lo inalcanzable.

Con audacia puede decirse que, por lo tanto, es impropio ser aristotélico o tomista o hegeliano. Corresponde la gratitud a los maestros y hasta en la filosofía más descabellada para uno algo se cosecha, como decía el aquinate. Sin embargo, pedirle a un solo autor toda la sabiduría, resulta un despropósito dado que, como muestra la experiencia, cada concepción se ha urdido delante de unas preocupaciones y unas ilusiones que el más superlativo de los talentos no podría trascender. Una filosofía es una expresión de amor al mundo que nos toca en la medida en que pensarlo es una forma, la más humana, de habitarlo. Es imposible, pues, que una sola visión resuelva las incógnitas que suscitaría otro presente que, como el nuestro, es el único tiempo que ocupamos, por lo 
demás distinto e irrepetible, y solo entendiéndolo podríamos vivir plenamente en él.

Para Montaigne, el encierro en el castillo es solo otra alternativa de este tránsito constante. No una suspensión de los desplazamientos. El cuerpo se recoge, el yo queda en custodia. Pero, en esa deliberada soledad, la interioridad extrema su sed y se halla de nuevo ante un universo intimo. Según Hans-Georg Gadamer, tenemos mundo en la medida en que lo poseemos con la palabra. Nuestras experiencias se constituyen por medio de la verbalización de que se vale la conciencia para tratar con lo vivido (Gadamer, 2005: 531).

El escepticismo montaigniano es la afirmación de una existencia pletórica en su imperfección, volcada sobre sí misma y agradecida en una tarea de autoposesión que no se impacienta con su irrevocable provisionalidad. Julieta hablaba de amor a Romeo suspirando: "sería pobre si pudiera contar mis caudales". Son felizmente incontables las vivencias e inaprehensible el propio espíritu y lo que con él colinda. Con nuestras manos diminutas tomamos puñados de lo acontecido y con ellos formamos un hato impredecible cada vez. De un modo o de otro, ensayamos una imagen, intentamos ser.

El tener en cuenta que una subjetividad no puede cubrir lo que hay fuera o lo que hay dentro, siempre andando como estamos, elimina esa escrupulosidad con que un carácter ansioso se incriminaría sus debilidades (recuérdese la crudeza con que Lutero deploraba la naturaleza humana y llamaba a la razón "ramera del diablo"). A esta concordancia con nuestra propia mortalidad, se debe un sentido del respeto cordial que destierra la hostilidad de las relaciones y convierte la coexistencia en una sincera acogida de los otros (Zweig, 2003: 61). ${ }^{7}$ Montaigne no se contentaría con

7 "Y mientras que los otros, los profesores de la Sorbona, los concilios, los legados, los Zwinglios y los Calvinos proclamaban 'Nosotros sabemos la verdad', la divisa de Montaigne fue ‘QQué sé yo?’ Y mientras ellos quería imponer con 
una tolerancia literal, como el soportarnos recíprocamente, y en su lugar preferiría el interés y la inclusión de los demás en nuestra composición del mundo. Decía Proust que el gran viaje no es hacia los confines de la tierra, sino hacia los ojos de nuestro semejante.

El de Montaigne es, por ello, un pensamiento oportuno para una era de globalización técnica y comercial que, además de arriesgar una desabrida uniformización cultural, tiene todavía pendiente una ética de la solidaridad. Kant había dicho con agudeza y sencillez que, "como todos estamos y nos movemos sobre la superficie de una esfera, no tenemos otro lugar adónde ir y estamos, por tanto, obligados a vivir para siempre en proximidad y compañía de otros" (Bauman, 2005: 162). No obstante, esta unidad planetaria no podría consistir en el solo consenso de unos cuantos principios jurídicos, de unas leyes de comercio o de los gustos de consumo. Debe llevar consigo, más bien, una verdadera dinámica de integración enraizada en el cultivo de la diferencia, acorde con que nuestra condición es siempre el reino de las posibilidades. Que la concurrencia urbana, en último término, no se restrinja a un estar unos junto a otros, sino que sea un efectivo y cotidiano unos con otros, parafraseando a Tocqueville, puesto que las discrepancias no solo no son incompatibles con la comunidad, sino que son, además, su sustento y su aliciente. "Quien me contraría despierta mi atención, no mi enojo", repite el maestro a caballo. Como Arendt acostumbraba a decir, no podemos aspirar a ser tan diferentes que no podamos entendernos ni tampoco tan semejantes que no tengamos qué comunicarnos.

la rueda y el destierro el ‘¡Así tenéis que vivir!', su consejo proclama: ¡Pensad vuestras ideas, no las mías! ¡Vivid vuestra vida! ¡No me sigáis a ciegas, manteneos libres! Quien piensa para sí libremente, respeta toda libertad sobre la tierra” (Zweig, 2003: 21). 


\section{Bibliografía}

Alighieri, Dante, 2004, La divina comedia, Ángel Crespo (trad.), Barcelona, Aguilar.

Arendt, Hannah, 1993, La condición humana, Ramón Gil Novales (trad.), Barcelona, Paidós.

Aristóteles, 1998, Metafísica, V. García Yebra (trad.), Madrid, Gredos.

Bauman, Zygmunt, 2005, Amor líquido. Acerca de la fragilidad de los vinculos humanos, Mirta Rosenberg y Jaime Arrambide (trad.), México, Fondo de Cultura Económica.

Bürger, Christa y Peter Bürger, 2001, La desaparición del sujeto. Una historia de la subjetividad de Montaigne a Blanchot, A. González Ruiz (trad.), Madrid, Akal.

Canetti, Elias, 2008a, Apuntes I, Juan José del Solar y Beatriz Galán (trad.), Barcelona, Debolsillo.

, 2008b, Apuntes II, trad. C. García Ohlrich, G. Dietrich, J. J. del Solar y B. Galán (trad.), Barcelona, Debolsillo.

Cusa, Nicolás de, 1984, La docta ignorancia, M. Fuentes Benot (trad.), Buenos Aires, Aguilar / Orbis.

Descartes, René, 1999, Discurso del método, Eduardo Bello R. (trad. y ed.), Madrid, Tecnos.

Flaubert, Gustave, 2003, Cartas a Louise Colet, Ignacio Malaxecheverría (trad.), Madrid, Siruela.

Gadamer, Hans-Georg, 2005, Verdad y método I, A. Agud A. y R. de Agapito (trad.), Salamanca, Sígueme.

Gilson, Etienne, 1998, La unidad de la experiencia filosófica, Carlos Balińas (trad.), Madrid, Rialp.

Lacouture, Jean, 2000, Montaigne a caballo, Ida Vitale (trad.), México, Fondo de Cultura Económica. 
Márai, Sándor, 2006, iTierra tierra!, J. Xantus Szarvas (trad.), Barcelona, Salamandra.

Montaigne, Michel de, 2007 Los ensayos, J. Bayod Brau (trad.), Barcelona, Acantilado.

Navarro, Jesús, 2007, Pensar sin certezas, Montaigne y el arte de conversar, Madrid, Fondo de Cultura Económica.

Popper, Karl, 2006, La sociedad abierta y sus enemigos, E. Loedel (trad.), Barcelona, Paidós.

Ribeyro, Julio Ramón, 2009, Las respuestas del mudo, Jorge Coaguila (sel.), Iquitos, Perú, Tierra Nueva.

Rotterdam, Erasmo de, 1999, Elogio de la locura, T. Suero Roca (trad.), Madrid, El Mundo Unidad Editorial.

Sciacca, Michele Federico, 1966, Estudios sobre filosofía moderna, J. J. Ruiz Cuevas (trad.), Barcelona, Luis Miracle.

Sófocles, Las siete tragedias, 2007, Ángel M. Garibay (trad.), México, Porrúa.

Todorov, Tzvetan, 2003, Delicias y deberes. Una vida entre fronteras. (Entrevistas con Catherin Portevin), Marcos Mayer (trad.), Buenos Aires, Fondo de Cultura Económica.

Zweig, Stefan, 2003, El legado de Europa, Claudio Gancho (trad.), Barcelona, Acantilado. 
